\title{
Sistem Pendukung Keputusan Pemberian Kredit Mikro Utama Pada Pt.Bank Bjb Kcp Cikande Dengan Metode Simple Additive Weighting (SAW)
}

\author{
Harsiti $^{1}$, Roikotuljanah ${ }^{2}$, \\ ${ }^{12}$ Program Studi Informasi, Fakultas Teknologi Informasi- Universitas Serang Raya \\ Jl. Raya Cilegon - Serang Km.5 Taman Drangong Kota serang - Banten, indonesia \\ ${ }^{1}$ harsitieyahoo.com \\ ${ }^{2}$ roikotuljanahegmail.com
}

\begin{abstract}
Sistem Pendukung Keputusan pemberian Kredit Mikro Utama Pada Bank bjb KCP Cikande merupakan suatu sistem interaktif yang mendukung keputusan dalam proses pengambilan keputusan melalui alternatif - alternatif yang diperoleh dari hasil pengolahan data, informasi dan rancangan model. Metode Simple Additive Weighting (SAW) sering juga dikenal dengan istilah metode penjumlahan terbobot. Konsep dasar metode Simple Additive Weighting (SAW) adalah mencari penjumlahan terbobot dari rating kinerja pada setiap alternatif pada semua atribut. Metode Simple Additive Weighting (SAW) membutuhkan proses normalisasi matriks keputusan.

Hasil dari penelitian ini adalah sebuah sistem pendukung keputusan pemberian kredit mikro utama pada PT.Bank bjb KCP Ciknade dengan menggunakan metode SAW. Sistem Pendukung Keputusan Pemberian Kredit Mikro Utama ini dapat menilai calon nasabah sesuai kriteria nasabah yang penilaiannya bersumber dari Bank bjb..
\end{abstract}

Kata kunci: SPK, Kredit Mikro Utama, Simple Additive Weighting

\section{LATAR BELAKANG}

Semakin tingginya minat masyarakat mendapatkan kredit membuat pihak Bank kesulitan menentukan siapa yang layak menerima kredit atau tidak, sulitnya mencari informasi sebagai referensi dalam pengambilan keputusan, serta adanya ketidaksesuaian antara kriteria pemohon kredit dan persyaratan yang diajukan. Merupakan suatu kendala yang sering terjadi. Oleh karena itu timbulah inisiatif untuk merancang suatu sistem yang dapat membantu pihak Bank dalam menentukan siapa yang layak menerima kredit mikro utama sesuai kriteria dengan menggunakan metode Simple Additive Weighting (SAW).

\section{DASAR TEORI}

\section{A. Unified Modelling Language (UML)}

Menurut Munawar (2005, P7-100) menyatakan bahwa, Unified modeling language (UML) adalah sebuah bahasa yang berdasarkan grafik / gambar untuk memanipulasi, menspesifikan, membangun, dan pendokumenantasian dari sebuah sistem pengembangan software berbasis OO (Object - Oriented)

B. Simple Additive Weighthing (SAW)
Menurut Yulison Herry Chrisnanto, Faiza Renaldi dan Kiki Purwati (2012) menyatakan, Metode SAW sering juga dikenal sebagai metode penjumlahan terbobot. Konsep dasar metode SAW adalah mencari penjumlahan terbobot dari rating kinerja pada setiap alternatif pada semua atribut. Metode SAW membutuhkan proses normalisasi matriks keputusan (X) ke suatu skala yang dapat diperbandingkan dengan semua rating alternatif yang ada.

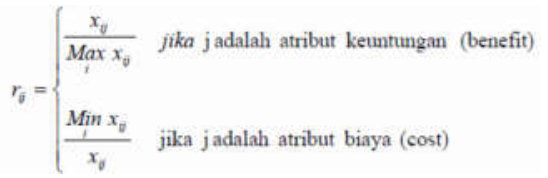

Xij: Baris dan kolom dari matriks

Dimana rij adalah rating kinerja ternormalisasi dari alternatif Ai pada atribut $\mathrm{Cj} ; \mathrm{i}=1,2, \ldots, \mathrm{m}$ dan $\mathrm{j}=1,2, \ldots, \mathrm{n}$.

Nilai preferensi untuk setiap alternative (Vi) diberikan sebagai:

$$
V_{i}=\sum_{j=1}^{n} w_{j} r_{i j}
$$

Gambar 2: Formula untuk mencari nilai preverensi

Vi : Nilai Akhir Alternative

Wi : Bobot yang telah ditentukan

Rij : Normalisasi matriks

Nilai Vi yang lebih besar mengindikasikan bahwa alternatif ai lebih terpilih.

\section{DESAIN PENELITIAN}

\section{A. Metodelogi}

Penelitian ini diawali dengan dengan pengumpulan data, yaitu data Kriteria, nilai setiap kriteria dan sub kriteria dari kriteria yang ada dalam kurung waktu 3 bulan. Data tersebut kemudian akan di olah dengan menggunakan metode Saw untuk menentukan pemohon yang layak menerima kredit. 
Perancangan sistem dilakukan dengan Unified Modelling Language (UML).

\section{HASIL DAN PEMBAHASAN}

Analisis pendukung keputusan dilakukan untuk menentukan pemohon yang layak menerima kredit.. Data yang diperoleh berdasarkan Kriteria - kriteria yang telah ditentukan bank, yaitu :

\section{A. Data Kriteria}

\begin{tabular}{|c|l|l|}
\hline C & \multicolumn{1}{|c|}{ Kriteria } & \multicolumn{1}{c|}{ Bobot } \\
\hline C1 & Penghasilan & 45 \\
\hline C2 & Karakter & 25 \\
\hline C3 & Jaminan & 20 \\
\hline C4 & Legalitas usaha & 10 \\
\hline
\end{tabular}

\section{B. Sub kriteria penghasilan}

\begin{tabular}{|c|l|l|}
\hline Kriteria & \multicolumn{1}{|c|}{ Sub Kriteria } & \multicolumn{1}{c|}{ Nilai } \\
\hline Penghasilan & $\begin{array}{l}\text { Rp. } 4.000 .000 \mathrm{~s} / \mathrm{d} \\
\text { Rp. } 5.000 .000\end{array}$ & 100 \\
\cline { 2 - 3 } & $\begin{array}{l}\text { Rp. } 3.000 .000 \mathrm{~s} / \mathrm{d} \\
\text { Rp. } 3.900 .000\end{array}$ & 80 \\
\cline { 2 - 3 } & $\begin{array}{l}\text { Rp. } 2.000 .000 \mathrm{~s} / \mathrm{d} \\
\text { Rp. } 2.900 .000\end{array}$ & 60 \\
\cline { 2 - 3 } & $\begin{array}{l}\text { Rp. } 1.000 .000 \mathrm{~s} / \mathrm{d} \\
\text { Rp. } 2.500 .000\end{array}$ & 50 \\
\hline & Rp. $500.000 \mathrm{~s} / \mathrm{d}$ & 30 \\
Rp. 900.000 & \\
\hline
\end{tabular}

C. Sub Kriteria Karakter

\begin{tabular}{|l|l|l|}
\hline Kriteria & Sub Kriteria & \multicolumn{1}{c|}{ Nilai } \\
\hline \multirow{2}{*}{$\begin{array}{l}\text { Karakter } \\
\text { (kepribadian }\end{array}$} & Sangat baik & 100 \\
\cline { 2 - 3 } nasabah $)$ & Baik & 80 \\
\cline { 2 - 3 } & Cukup & 40 \\
\cline { 2 - 3 } & Kurang & 30 \\
\cline { 2 - 3 } & Sangat kurang & 20 \\
\hline
\end{tabular}

\section{Sub Kriteria Jaminan}

\begin{tabular}{|l|l|l|}
\hline Kriteria & \multicolumn{1}{|c|}{ Sub Kriteria } & \multicolumn{1}{c|}{ Nilai } \\
\hline Jaminan & Surat tanah & 100 \\
\cline { 2 - 3 } & BPKB Mobil & 80 \\
\cline { 2 - 3 } & BPKB Motor & 60 \\
\cline { 2 - 3 } & SK PNS & 40 \\
\cline { 2 - 3 } & $\begin{array}{l}\text { Jamsostek dan } \\
\text { Ijazah }\end{array}$ & 20 \\
\hline
\end{tabular}

E. Sub Kriteria Legalitas usaha

\begin{tabular}{|l|l|l|}
\hline \multicolumn{1}{|c|}{ Kriteria } & \multicolumn{1}{|c|}{ Sub kriteria } & \multicolumn{1}{c|}{ Nilai } \\
\hline $\begin{array}{l}\text { Legalitas } \\
\text { Usaha } \\
\text { (pekerjaan) }\end{array}$ & Wirausaha & 100 \\
\cline { 2 - 3 } & Pensiunan & 80 \\
\cline { 2 - 3 } & Buruh Pabrik & 40 \\
\hline
\end{tabular}

\section{F. Alternative}

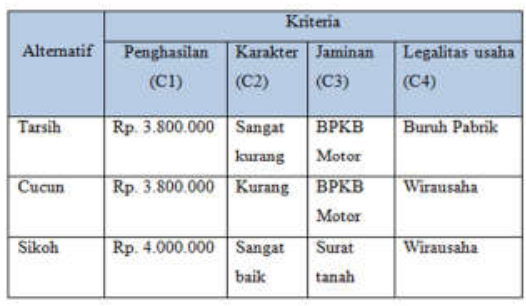

Rating Kecocokan Setiap Alternatif Pada Setiap Kriteria.

\begin{tabular}{|l|l|l|l|l|}
\hline \multirow{2}{*}{ Altematif } & \multicolumn{5}{|c|}{ Kriteria } \\
\cline { 2 - 5 } & $\begin{array}{c}\text { C1 } \\
\text { (MAX) }\end{array}$ & $\begin{array}{c}\text { C2 } \\
(\text { MAX) }\end{array}$ & $\begin{array}{c}\text { C3 } \\
(\text { MAX) }\end{array}$ & $\begin{array}{c}\text { C4 } \\
\text { (MAX) }\end{array}$ \\
\hline A1 & 80 & 20 & 60 & 40 \\
\hline A2 & 80 & 30 & 60 & 100 \\
\hline A3 & 100 & 100 & 100 & 100 \\
\hline
\end{tabular}

Langkah - Langkah Penyelesaian

1. Vektor bobot: $\mathrm{W}=[45,25,20,10]$

2. Matrik Keputusan $\mathrm{X}$ berdasarkan kriteria bobot

$$
X=\left\{\begin{array}{cccc}
80 & 20 & 60 & 40 \\
80 & 30 & 60 & 100 \\
100 & 100 & 100 & 100
\end{array}\right\}
$$

3. Normalisasi matriks $\mathrm{X}$ menggunakan persamaan 1

$$
R i j=\frac{\mathrm{X}_{\mathrm{i} i}}{\mathrm{Max} \cdot \mathrm{X} i j}
$$




\section{Altematif A1}

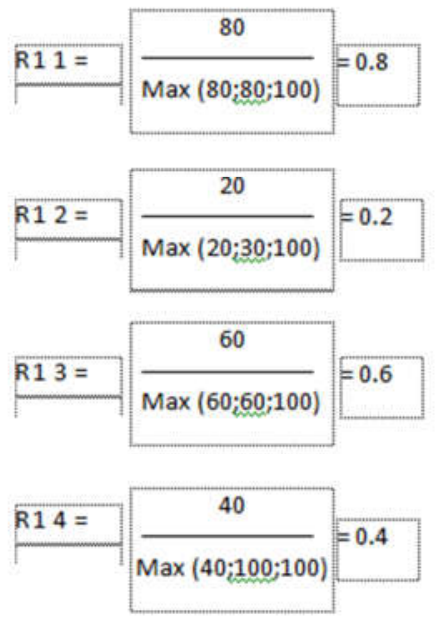

Altematif A2
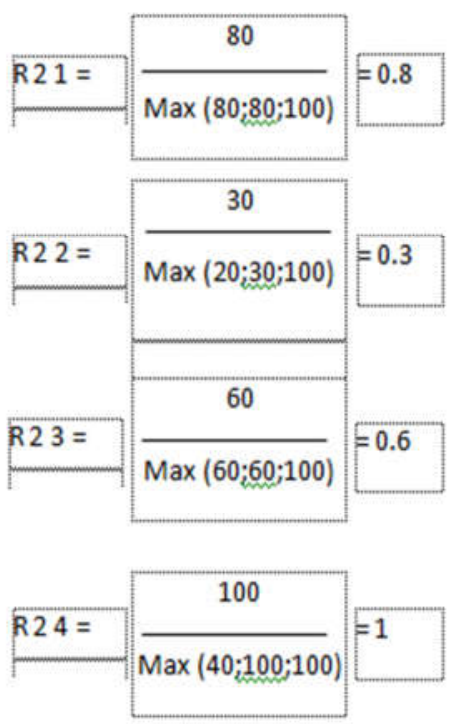

\section{Alternatif A3}

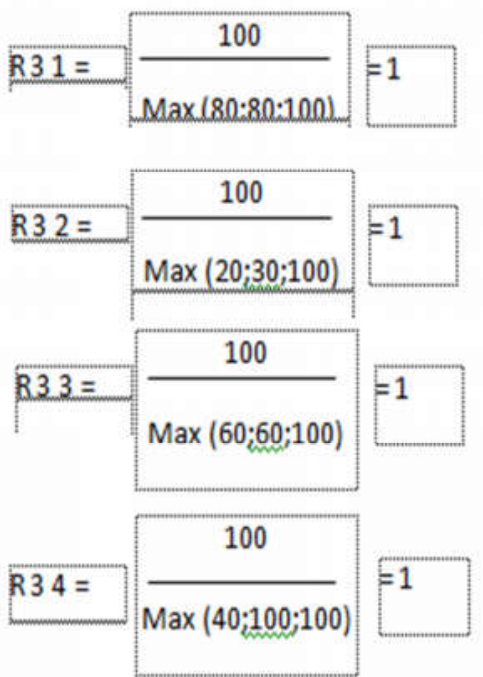

Dari hasil perhitungan di atas maka di dapat matriks ternomalisasi R sebagai berikut :

$$
\mathrm{X}=\left\{\begin{array}{cccc}
0.8 & 0.2 & 0.6 & 0.4 \\
0.8 & 0.3 & 0.6 & 1 \\
1 & 1 & 1 & 1
\end{array}\right\}
$$

1. Mencari alternatif terbaik menggunakan persamaan 2

$$
\begin{aligned}
& V 1=(0.8 \times 45)+(0.2 \times 25)+(0.6 \times 20)+(0.4 \times 10)=57 \\
& V 2=(0.8 \times 45)+(0.3 \times 25)+(0.6 \times 20)+(1 \times 10) \quad=65.5 \\
& V 3=(1 \times 45)+(1 \times 25)+(1 \times 20)+(1 \times 10) \quad=100
\end{aligned}
$$

V3 merupakan peringkat pertama karena memiliki nilai yang lebih besar dari nilai lain, V3 merupakan nilai preferansi dari alternatif A3, sehingga A3 atau dalam kasus ini pemohon kredit bernama Sikoh yang menjadi alternatif terbaik.

\section{Implementasi Sistem penilaian kredit mikro utama}

Form penilaian kredit mikro utama adalah form yang digunakan untuk menginputkan Data pemohon, dan menginputkan data penilaian perkriteria dari pemohon kredit. 


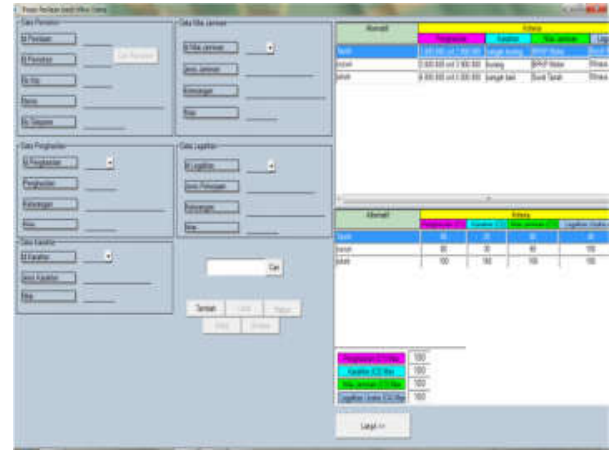

Gambar 4.8 implementasi penilaian kredit mikro utama

\section{Implementasi Analisa Penilaian SAW}

Form analisa penilaianan SAW adalah form yang digunakan untuk memproses penilaian, kemudian menampilkan hasil penilaian penentuan layak menerima kredit.

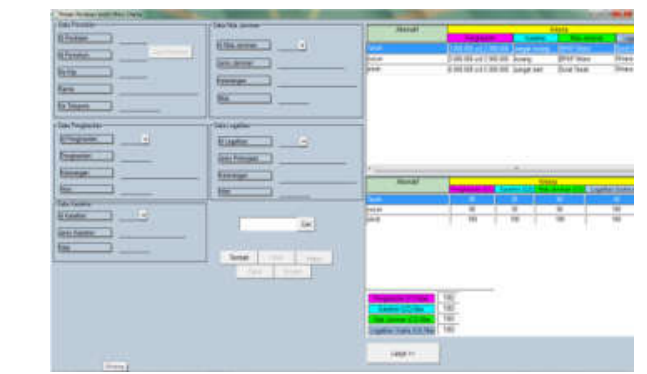

Gambar 4.9 implementasi analisa penilaianan SAW

\section{KESIMPULAN}

Sistem Pendukung Keputusan Pemberian Kredit Mikro Utama Pada Bank Bjb KCP Cikande dibangun berdasarkan kriteria yang ditentukan oleh Bank serta menentukan nilai bobot dari masing - masing kriteria,

Penelitian ini menghasilkan sebuah aplikasi yang dapat memberikan referensi kepada pihak Bank dalam menentukan calon penerima kredit mikro utama sesuai kriteria dengan menggunakan metode Simple Additive Weighting (SAW).

\section{DAFTAR PUSTAKA}

[1] Chrisnanto, Yulison Herry, et al (2012). “ Sistem Pendukung Keputusan Berbasis Web Dalam Memilih Produk Telepon Genggam Menggunakan Metoda Simple Additive Weighting”. Seminar Nasional Teknologi Informasi dan Komunikasi. ISBN 978 - 602 - 19837 $0-6$

[2] Eniyati, Sri. (2011).” Perancangan Sistem Pendukung Pengambilan Keputusan untuk Penerimaan Beasiswa dengan Metode SAW (Simple Additive Weighting)". Jurnal Teknologi Informasi DINAMIK. Vol.16. No.(2)

[3] Ernain, et al. (2011). "Sistem Pendukung Keputusan Pembiayaan Mikro Berbasis Client Server Stusi Kasus
Pada Perusahaan Pembiayaan Bandar Lampung”. SeminarNasional Aplikasi Teknologi Informasi. ISSN $1907-5022$

[4] Hermanto, Nandang.(2012). "Sistem Pendukung Keputusan Menggunakan Metode Simple Additive Weighting (Saw) Untuk Menentukan Jurusan Pada Smk Bakti Purwokerto". Seminar Nasional Teknologi Informasi \& Komunikasi.. ISBN 979 - 26 - 0255 - 0

[5] Indrawaty, Youllia, et al. (2011). "Implementasi Metode Simple Additive Weighting Pada Sistem Pengambilan Keputusan Sertifikasi Guru". Jurnal informatika. Vol. 2. No.(2)

[6] Munawar.(2005). Pemodelan Visual dengan UML. Yogyakarta: Graha Ilmu

[7] Munthe, Hotmaria Ginting .(2013). "Sistem Pendukung Keputusan Penentuan Prioritas Usulan Sertifikasi Guru Dengan Metode Simple Additive Weighting". Jurnal informatika. Vol. IV. No.(2). 1-7

[8] Nugroho, Adi, Munawar. 2005. View dan UML, Jakarta

[9] Pato, Saduldyn. (2013). "Analisis Pemberian Kredit Mikro Pada Bank Syariah Mandiri Cabang Manado". Jurnal EMBA. Vol.1. No.(4). 875-885

[10] Puspitasari, Maya dan Singgih Moses Laksono. (2012). "Analisa Dan Perbaikan Sistem Evaluasi Kelayakan Pengambilan Kredit Di Bank Syariah X". Prosiding Seminar Nasional Manajemen Teknologi XIII. Surabaya.

[11] Turban, et al.(2005,P64). (TesisBinus.ac.id) /eColls/ Doc/Bab2/2010-2-00441-SIASbab2,Pdf. Sabtu, 13 september 2014 14:19

[12] Turban, Efraim, et al. (2001). Ting peng, Decision Support System and Intelligent System. 6th Edition. Upper Saddle River: pretice-Hall 